\title{
A case of rhizomelic chondrodysplasia punctata
}

\author{
Biplab Maji ${ }^{1}$, Apurba Ghosh ${ }^{2}$, Lipi Shekhar Singh ${ }^{3}$
}

Sri Lanka Journal of Child Health, 2013; 42: 226

(Key words: rhizomelic chondrodysplasia punctata)

Rhizomelic chondrodysplasia punctata (RCDP) is a rare autosomal recessive syndrome characterized by punctuate calcifications of the epiphyseal cartilage with proximal limb shortening, joint contractures, cataracts, failure to thrive, and severe mental-motor retardation ${ }^{1}$.

\section{Case report:}

A male infant born at 39 weeks of gestation to unrelated parents had a birth weight of $2300 \mathrm{~g}$, a birth length of $41 \mathrm{~cm}$ and a head circumference of $31 \mathrm{~cm}$. At birth, facial dysmorphism comprising prominent forehead, upslanting palpebral fissures, broad nasal bridge, long philtrum, thin upper lip, short neck and shortened proximal limbs of all four extremities were noted (figure 1).

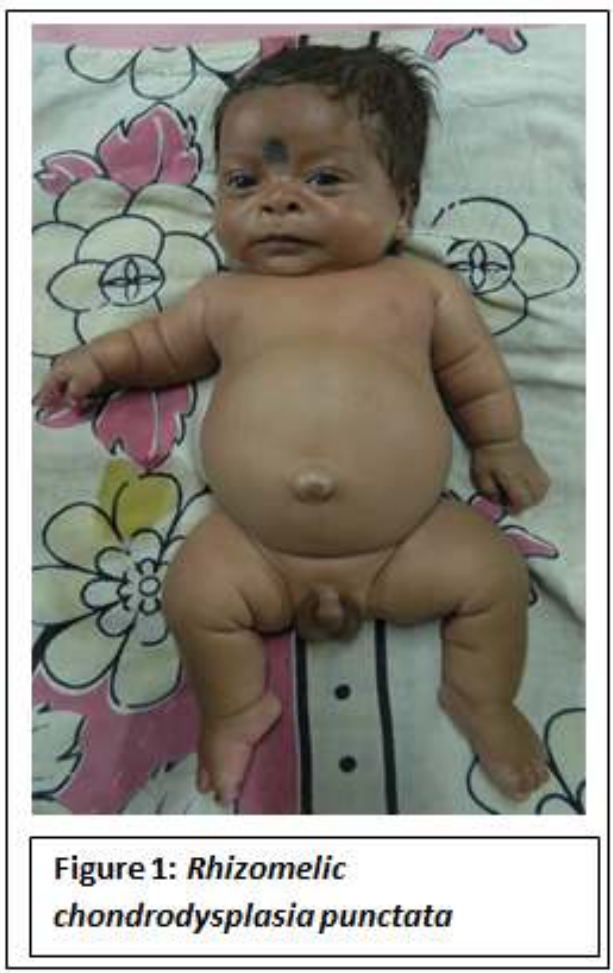

${ }^{1}$ Postgraduate Trainee in Paediatrics, ${ }^{2}$ Professor and Director, Institute of Child Health, Kolkata, India, ${ }^{3}$ Internee, Medical College, Kolkata, India.

(Received on 16 April 2013: Accepted after revision on 17 May 2013)

Limb radiographs showed shortening of humeri and femora, multiple punctate calcific stippling of joints in shoulders, elbows (figure 2) ribs, hips, knees (figure 3) and posterior segments of vertebra with coronal fissures of cervical and thoracic vertebral bodies.
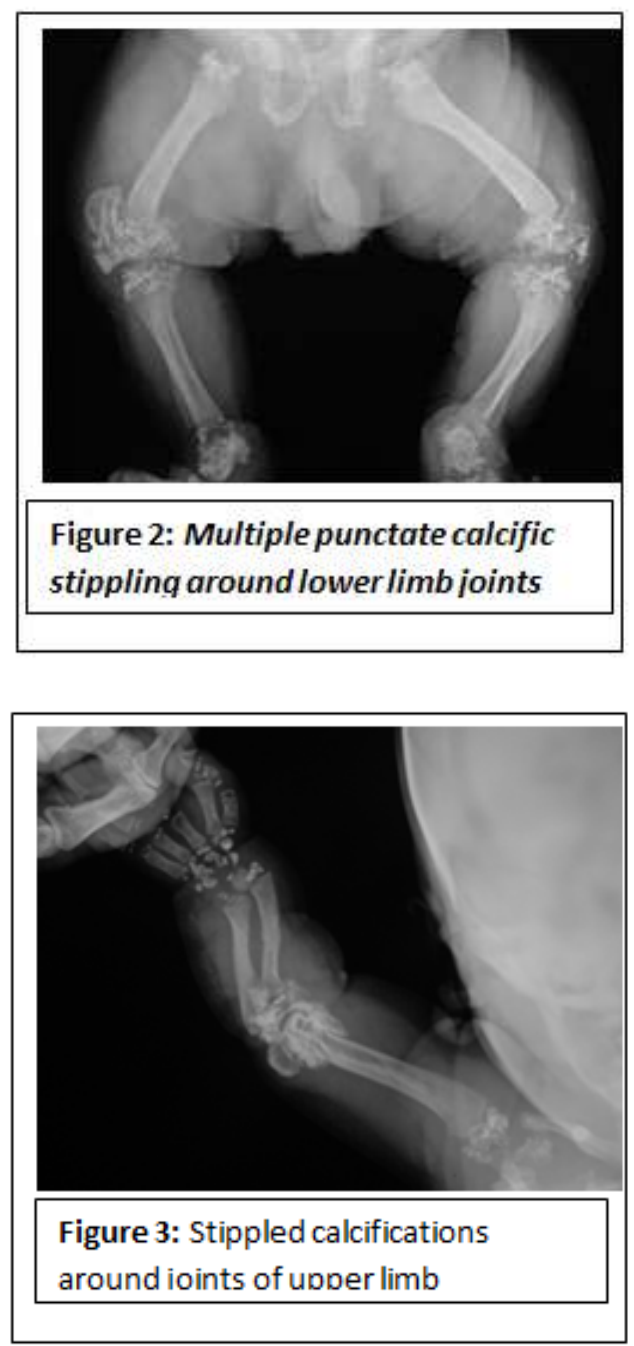

\section{References}

1. Naher BS, Mannan MA, Noor K, Shahidullah MD. Chondrodysplasia punctata in a newborn; rhizomelic type: a case report. Bangladesh Journal of Child Health .2010; 34 (1): 28-30. http://dx.doi.org/10.3329/bjch.v34i1.5700 